\title{
'I Can Lead the Life That I Want to Lead': Social Harm, Human Needs and the Decriminalisation of Sex Work in Aotearoa/New Zealand
}

\author{
Lynzi Armstrong ${ }^{1}$ (1)
}

Accepted: 10 June 2021

(c) The Author(s), under exclusive licence to Springer Science+Business Media, LLC, part of Springer Nature 2021

\begin{abstract}
Background Sex work is commonly understood to be a risky occupation. Sex work law debates coalesce around the issue of harm, with differing perspectives regarding what constitutes harm, how harm is produced and what needs to change to mitigate it. While sex work is often portrayed as inherently harmful, sex workers and researchers have challenged this assumption, calling attention to the relationship between harm and policies in place. Criminalisation, in its many and varied forms, is thought to exacerbate harms that can occur in sex work, while decriminalisation is understood as creating conditions conducive to minimising harm. However, the decriminalisation of sex work remains rare, and more research which examines how decriminalisation works in relation to harms is critical. This paper uses the concept of social harm to unpack the implications of sex work policies and examine the experiences of sex workers in New Zealand, where sex work is decriminalised. Methods Semi-structured in-depth interviews were conducted with 46 sex workers in New Zealand in 2018 and 2020 across two studies focused on examining experiences and perceptions of stigma and discrimination in this context. The interviews were thematically analysed using NVivo data analysis software.

Results The experiences of participants demonstrate how involvement in sex work had improved their lives in multiple ways. Participants described the importance of sex work in improving their quality of life by ensuring that they could better meet their everyday needs, the autonomy this afforded them and how decriminalisation helped to enable this. The validating impact of decriminalisation in acknowledging sex workers as people with rights is also evident in participant's experiences. Conclusions Social harm is a framework that can help illuminate socio-economic harms which influence pathways into sex work for some people and the compounding harms of criminalising regimes. The benefits of engaging in sex work are often overlooked in policy debates. Although sex work is not easy work, engaging in sex work can have positive impacts on the lives of people who pursue it. Full decriminalisation of sex work is the only responsible option for societies seeking to reduce harm.
\end{abstract}

Keywords Sex work $\cdot$ Social harm $\cdot$ Decriminalisation $\cdot$ Human needs $\cdot$ New Zealand

\section{Introduction}

Sex work law is contentious internationally, owing to a long history of criminalisation which has positioned prostitution as deviant and dangerous. In most countries, the sex industry remains either fully or partially criminalised. However, New Zealand forged a different path in 2003 with the passing of the Prostitution Reform Act (PRA), which decriminalised sex work for permanent residents and citizens. In recent

Lynzi Armstrong

Lynzi.armstrong@vuw.ac.nz

1 School of Social and Cultural Studies, Victoria University of Wellington, PO Box 600, Wellington 6140, New Zealand years, debates regarding sex work laws and the possibility of legislative change have intensified internationally. Within these debates, New Zealand's decriminalised framework is frequently juxtaposed against another legislative approach, often referred to as the 'end-demand' approach, or 'the Nordic model'. ${ }^{1}$ The New Zealand model means that sex workers, their clients and other third parties can operate without the risk of criminalisation, providing these interactions comply with the PRA (see Prostitution Reform Act, 2003 for more details). The overarching rationale for the PRA was

\footnotetext{
1 While Nordic model is so termed due to variants of this approach being initially adopted in Nordic region countries, it is important to acknowledge that the inconsistent way that the approach is implemented means it is inaccurate to refer to a single 'Nordic model' (See Kingston and Thomas, 2019 for further explanation).
} 
harm minimisation, based on the argument that decriminalisation could help to reduce harms that can occur in sex work (Abel et al., 2007). The Nordic model, by comparison, is centred on criminalising clients and other third parties, in a bid to repress the sex industry by 'ending demand' for sex worker's services (Östergren, 2017).

Debates regarding the relative merits of these different approaches to sex work law are highly polarised, owing to differences in how the sex industry is understood. Those who advocate for a decriminalised model commonly see sex work as a form of labour, while those who seek to criminalise clients and other third parties consider prostitution to be a form of violence that is symbolic of women's subordination in society. Within these debates, the issue of harm looms large. Those advocating for end-demand laws conceptualise prostitution as inherently harmful - a form of violence in itself (see for example Jeffreys, 1997; Farley, 2004). Those who campaign for full decriminalisation and see sex work as work do not deny the harm that can occur in sex work. However, much of these potential harms are understood to be interlinked with policies in place, which can either exacerbate or minimise harms (see for example Sanders \& Campbell, 2014; Sanders, 2016; Vanwesenbeeck, 2017). Research on the impacts of the New Zealand model has indicated that decriminalisation helps to reduce risks of harm that can occur in sex work, while evidence from countries in which variants of the Nordic model are in place signals that this approach is harmful to sex workers in a myriad of ways (Abel, 2014; Armstrong, 2016; Ellison et al., 2019; Levy, 2014; Vuolajärvi, 2019). Research conducted in New Zealand post decriminalisation found that the law change helped sex workers to feel more able to refuse to see clients that they did not want to see, while also feeling that their rights had been strengthened by the legislation and that they were more in control in interactions with clients (Abel et al., 2007; Abel, 2014). Subsequent studies have indicated that decriminalisation better supports the safety strategies of street-based sex workers and has significantly improved their experiences interacting with police (Armstrong, 2014, 2016). Furthermore, several landmark cases and events reported in the media have demonstrated the power of decriminalisation. Two sex workers winning sexual harassment cases against brothel operators, a conviction of rape handed down to a client who covertly removed a condom, and the National Coordinator of the New Zealand Prostitutes Collective being awarded a Damehood for services to the rights of sex workers are just a few of many examples that point to decriminalisation not only strengthening protection from harm and access to justice, but also recognising sex workers as valued members of society (Duff, 2014; Livingstone, 2020; Wellington District Courts Reporter, 2021; Mason, 2018). It is important to acknowledge that the New Zealand model of decriminalisation is far from perfect. A significant flaw of the PRA is Sect. 19 of the legislation, which prohibits temporary migrants from working in the sex industry, meaning that they are excluded from the laws' protections (see for more details Armstrong et al., 2020; Bennachie et al., 2021). However, the existing evidence clearly indicates that those who are covered by the legislation are safer and have more rights than sex workers did pre-decriminalisation and compared to those working elsewhere under criminalising regimes. Despite this evidence, advocates of the Nordic model continue to argue that full decriminalisation is harmful and portray the New Zealand model as a catastrophic failure (for examples of this see Armstrong, 2020). Such speculation and ongoing debates regarding sex work policies means that continuing to build the evidence base on the impacts of sex work laws is essential, along with nuanced examinations of harm in these different contexts.

In this paper, I use social harm as a lens to illustrate how different approaches to sex work policy operate in relation to harm, with a focus on the decriminalisation of sex work. The aim of this paper is to examine the utility of social harm as a framework through which to understand sex work policies and their impacts. Using the decriminalisation of sex work in New Zealand as a case study, I argue that social harm provides a particularly fruitful lens to make sense of sex work laws. The social harm approach also enables a broader range of harms produced by the state to come into view, demonstrating how all forms of criminalisation compound these harms, strongly illustrating how decriminalisation works as a protective and liberating framework.

\section{Social Harm: a Brief Overview}

The origins of the social harm approach relate to frustration with the limited parameters of criminology, within which 'harm' has typically been defined as criminal acts. Social harm emerged from a desire among scholars for expansion beyond criminal harm, to include diverse forms of harm that-while not always publicly recognised as wrongdoing - can have significant adverse impacts on people's lives (Hillyard et al., 2004). While the seeds were sown for this perspective in the 1940s through Sutherland's expansive work on white collar crime, it is only in the last 30 years that the social harm approach has been named and has undergone extensive theoretical development (Hillyard et al., 2004; Sutherland, 1945). Much scholarly work to date has involved critical discussion of the scope of social harm and its conceptual parameters (see for example Hillyard \& Tombs, 2004, 2007; Lasslett, 2010; Pemberton, 2007; Soliman, 2019; Yar, 2012). The overarching purpose of the social harm approach is to provide a theoretical framework that can illustrate how harms experienced by individual people are not typically a direct result of their behaviours or choices, but rather a consequence of how societies are organised (Pemberton, 2007). While social harm has undergone much conceptual development, with clearer and expanded definitions of its scope, only in recent years have researchers applied the concept in empirical studies. Specifically, 
social harm has been used to critically examine migration control practices, working conditions in the service economy, the criminalisation of HIV transmission and police enforcement of drug laws, powerfully illustrating how policies that are (in some cases) well-intentioned can result in significant harm (Ashford et al., 2020; Canning, 2019; Lloyd, 2018; Mason, 2019). However, social harm has yet to be applied to sex work studies. In providing a lens through which to "critically explore the culpability of well-meaning state interventions in the (re)production of structural inequalities' (Mason, 2019: 382), social harm provides a particularly useful framework with which to unpack how sex work laws operate and how they impact sex workers.

\section{Defining Social Harm and its Application to Sex Work Policies}

A key critique of the social harm approach is that it is particularly broad and lacks a clear definition. Hillyard and Tombs (2007) conceptualise social harm as incorporating acts that result in physical harms (e.g. assaults), financial/ economic harms (e.g. poverty) and emotional/psychological harms (e.g. the damaging effect of stop and search policies on Muslim communities and young black men). However, scholars have subsequently proposed more detailed definitions to further clarify the conceptual parameters.

Yar (2012) proposed a definition based on Honneth's theory of recognition. Honneth (1995) argued that humans are dependent on the recognition of others to realise their sense of self, and recognition is accessed via three base modeslove, esteem and rights. Yar proposed that when the necessary pre-conditions to meet these needs are not enabled due to structural factors and processes, then these impediments can be conceived of as harms (Yar, 2012). Yar's definition equates social harm with disrespect vis-à-vis these recognative needs not being met.

Yar's proposed framework has been critiqued for its reliance on Honneth's theory of recognition, which Soliman (2019) argues side-lines structural factors which lead to inequality. Soliman bases this critique on the work of Nancy Fraser, who in theorising social justice argues that a focus on solely on recognition individualises the problem and obscures the structural conditions underpinning inequality. Thus, Fraser posits that the state must address complicity in misrecognition through policies which marginalise specific people. Accordingly, a vision for social justice must incorporate both misrecognition and maldistribution as these are dependent on each other (Fraser, 2003; Soliman, 2019). Thus, Soliman argues that it is critical for a social harm approach to not only list harms through misrecognition produced by state practices, but also identify and highlight the broader processes that drive these practices and maintain unequal societies (Soliman, 2019).
While social harm has not been specifically named as a framework for making sense of sex work policies, sex work scholars have usefully drawn on recognition as a conceptual frame through which to understand the process and impacts of sex work policy making, including a focus on social and economic redistribution. Abel (2018) for example has argued that New Zealand pursued a 'politics of recognition' in decriminalising sex work, but that more work needs to be done in the form of redistributive politics to achieve social justice (2018, p. 131). Laing and O'Neill (2018) drew on Honneth's theory of recognition in their analysis of the Bedford decision ${ }^{2}$ in Canada, arguing that the outcome was based on it being recognised that sex workers' status as citizens was violated by unconstitutional laws pertaining to their work and their subjugation. Sex workers challenged this situation in court, O'Neill and Laing note, by documenting their experiences of disrespect and hurt. As such, they pushed back against the partial citizenship status that they had been assigned through law. This also echoes Scoular and O'Neill's (2007) description of the 'fractured citizenship' that sex workers are afforded in the context of criminalising regimes. While not directly referring to the social harm approach, these existing analyses clearly illustrate the value of using recognition as a concept to understand both the process of sex work policy-making and the impacts of laws.

However, there are also broader social harm approaches that offer a valuable lens to sex work studies scholars making sense of the relationship between harms and sex work policies, which build in a focus on misrecognition in addition to capturing other sources of harm. Pemberton's (2015) human needs framework argues that fundamental human needs include physical and mental wellbeing, personal autonomy and the ability to form and maintain positive relationships with others. Social harm, Pemberton argues, arises when these fundamental needs are not met due to the structure and organisation of societies. Harms are categorised as being preventable-outcomes that could be avoided if a different course of action were taken at a societal level. For example, Tyler (2020) argues that in carefully designing and managing a project of 'disaster capitalism' over the past two decades, the British government has pushed already poor communities into circumstances of precarity and vulnerability that resemble post-war conditions (Tyler, 2020). The social harm approach enables the harmful actions of governments to be illuminated and the resulting consequences to be seen as what they are-preventable harms. Pemberton's framework for understanding what constitutes social harm

\footnotetext{
${ }^{2}$ Canada (AG) v Bedford was a Supreme Court of Canada decision in support of three current and former sex worker applicants, who argued that laws pertaining to sex work were unconstitutional and violated their rights.
} 
is powerful in enabling a diverse range of harms within societies to come into view.

Pemberton groups social harms into three broad categories: physical/mental health harms, autonomy harms and relational harms. Physical/mental health relates broadly to quality of life, including the ability to access healthcare and high-quality nutrition, access to housing, a feeling of control over one's life and a strong sense of self. Physical/mental health harm arises when societal factors such as laws, policies and economic conditions act as an impediment to these needs being met. Autonomy harms arise when people are not afforded control over their circumstances, where they are not allowed to participate in decisions about their lives and when their work is under-recognised and poorly rewarded. Relational harms stem from social exclusion and isolation, marginalisation and the misrepresentation of identities through stigma which erodes self-esteem and can result in internalised shame and guilt (Pemberton, 2015).

This definition of social harm offers clear benefits for identifying the range of harms that sex workers can experience, and to evaluate how different policy responses serve to produce, exacerbate or mitigate harms. Laws which prohibit brothel keeping, for instance, force sex workers to work in isolation if they wish to work legally, which renders them more vulnerable to being targeted with violence (Marsh, 2019). The alternative is breaking the law and working with others, risking a criminal conviction. Both situations carry serious risks of harm, are detrimental to mental wellbeing and do not afford sex workers control over their work environment. The ability to flourish as a human being is significantly undermined for sex workers in this context, and personal autonomy is restricted. Policies which criminalise clients are specifically intended to eliminate the business of sex workers, thus driving them into economic situations in which they are worse off and must seek alternative options to meet their everyday needs. This is clearly not conducive to physical or mental health. Furthermore, all forms of criminalisation label sex workers as 'different', thus stigmatising sex workers, which is a clear relational harm. When sex workers are already living in harmful societies, in which austerity measures or similarly oppressive social and economic policies inhibit the extent to which fundamental human needs can be met, laws which criminalise and/or seek to make sex work less accessible in a myriad of ways compound these existing harms.

\section{Methods}

This paper is based on interviews undertaken for two projects focused on sex workers' perceptions and experiences of stigma, discrimination and diverse legislative frameworks. The first set of interviews were conducted between January and May 2018. The second set were undertaken between February 2020 and August 2020. A total of 46 in-depth interviews were conducted with sex workers in New Zealand across the two projects. The interviews focused on a range of topics relating to stigma, discrimination and sex work laws, though due to the semi-structured approach, a range of important insights emerged pertaining more broadly to experiences of working in the decriminalised context.

Ethical approval for the research was granted by Victoria University of Wellington Human Ethics Committee. Owing to the sensitivity of the topic, privacy and confidentiality were prioritised throughout both projects. All names used are pseudonyms, and participants were given the option of choosing their own pseudonym so that they could identify themselves in any subsequent publications. Interviews were recorded with the participants' consent and were transcribed verbatim. Participants had the option of receiving a copy of their transcript to read and comment on and could request edits if they had any concerns about privacy. Great care has been taken to ensure there are no potentially identifying details in direct quotes or descriptions of participants.

All interviews took place in a private space that was mutually agreed with the participant or online using Zoom and Skype when restrictions were in place during the COVID-19 pandemic. A total of 8 participants were interviewed remotely online, while the remaining 38 were interviewed in person. The majority of interviews were conducted by Armstrong (30), while 16 were conducted by a research assistant employed to support the fieldwork.

Participants were primarily based in Wellington, Auckland, Christchurch and Rotorua-although several participants toured throughout New Zealand. Most of the participants were cisgender women (34), while five were cisgender men and seven transgender, gender diverse and/ or non-binary. At the time of the interview, 39 participants were primarily working indoors either in brothels/agencies or as independent workers, while seven were street based. However, several participants had experience of more than one sector. Just over half of participants identified their main ethnicity as New Zealand European or Pakeha ${ }^{3}$ (25), while 11 were Māori and one Samoan. Nine participants had lived a significant portion of their lives outside of the New Zealand and Pacific region in countries located throughout the Global South and beyond.

Owing to many years having passed since sex work was decriminalised, most of the participants had begun working in the sex industry post-decriminalisation; however, ten had also worked in the industry before the law changed. Thus, while a minority, the project benefited

\footnotetext{
3 Pākehā is a Māori language term to describe New Zealanders who are primarily of European descent.
} 
from the insights of sex workers who worked in the sex industry both prior to and after decriminalisation.

After transcripts were finalised with participants, each transcript was read in depth for data familiarisation as the first step of a reflexive thematic analysis. For this paper, a combined deductive and inductive approach to coding was used, using notes taken during interviews and data familiarisation and drawing from Pemberton's (2015) framework for conceptualising social harm. The interviews were coded using NVivo data analysis software, exploring how participants constructed the impact that sex work had in their lives and how they experienced working in the decriminalised framework. Following this process, broader themes were developed and reviewed.

\section{Results}

\section{Physical and Mental Health Harms: Undermining vs Enabling Survival}

Capitalist societies, Pemberton (2015) argues, produce a myriad of physical and mental health harms, through a focus on productivity resulting in long hours, repetitive physical tasks, financial insecurity and the associated physical and mental stress. Although New Zealand has a reputation for social innovation and is recognised as pioneering in its sex work policy, as Abel (2018) has argued, New Zealand is a neoliberal society and as such is still mired by socio-economic inequality, poverty and social exclusion. In line with this, while participants in this project cited diverse pathways and motivations for doing sex work, economic need and a desire for a better quality of life were a common theme among those interviewed. It is well-documented that living in poverty is hugely detrimental to physical and mental health (Knifton and Ingles, 2020). Several participants described their involvement in sex work as a strategy that they had chosen to improve their financial situation, and also described ways in which sex work had benefitted them both mentally and physically. Rose, who lives with a chronic illness, described deciding to do sex work because they recognised the financial deprivation they were experiencing and how this was impacting their health. They saw sex work as a way of changing this for the better:

....in my inner world I had kind of like that journey of [realising] 'you know what I'm not getting provided for. I haven't found a significant other to help me be provided for, I haven't got enough income from the government to provide for me'. I was like having seizures in the middle of the city because I'd get there and then my body would be too tired and then I couldn't get on my bus to get home so I was like paying for like Ubers and that's more expensive than petrol, but I didn't have enough to buy a car. So, I was in this weird stuck state where I' $m$ like 'something has to give'. And yep, that was it. I don't even remember my first client because it wasn't that special for me. Like it felt really normal - it didn't feel weird, it didn't feel awkward, I wasn't used or abused, I wasn't hurt...I just had someone that was like a normal human being who was like 'here's the money'. And I didn't feel dirty or weird. I was just like was like 'oh my god this [money] is going to replenish me'. (Rose)

Kate described first doing sex work in Australia because she was unemployed and in debt, explaining 'I had no money, like it was ridiculous, it was really a shit situation'. Economic hardship was a key factor for several participants in their decision to engage in sex work. However, this existed on a continuum. For a few participants, involvement in sex work was for the purposes of what Starr described as 'pure survival', helping them to access basic everyday necessities. However, for others, sex work enabled them to improve their economic situation so that they were not only surviving but enjoying an improved quality of life. Kate, for example, described using sex work to pull herself out of poverty. Once she had become more financially secure, she moved to New Zealand where she became employed outside of the sex industry and returned to study. However, although she was clear that she did not enjoy sex work, she decided to return to it because it afforded her a higher standard of living than the other job that she had been doing. She explained:

So, when I decided to go back and do study, I had some money and I thought 'I'll just go and do hospital work', because I used to do hospital work. And I went and did some of that and the pay rate was so awful. I was like 'I can't live like this'. So, then I thought, it [sex work] is going to be the best thing to do, yes. It was easier. (Kate)

This account of sex work being better for quality of life in comparison to other forms of work was common among several participants. As discussed earlier in this paper, advocates of end-demand policies are critical of decriminalisation and argue that instead women should be supported to exit the sex industry (Scoular \& Carline, 2014). Central to this is presumably an assumption that forms of work outside of the sex industry will be less exploitative and more fulfilling. However, the experiences of sex workers who participated in this study clearly refute this assumption. Sophie described her previous experiences working for the minimum wage as having been challenging and tiring, and that she found sex work as a way of exiting survival mode and living a better life. She explained: 
I was just sick of not having money and it's just so tiring like living kind of week to week. Yep. So, I was just kind of scheming and thinking how can I make extra money? Because, you know, I don't just want to survive-I want to like travel and I want to be able save and not have this move to New Zealand be like a giant backward step (Sophie)

In addition to the economic benefits of doing sex work, Olivia felt that she was treated more fairly than she had been in part time jobs outside of the sex industry, explaining 'I feel it's probably the job that I am most supported by my employer. I guess it's a job where I don't feel that I'm kind of taken advantage of because I'm a student.' Sex work was also described by participants who experienced mental illness as a better form of work for the management of their health condition. Bella felt that the flexibility of sex work enabled her to manage her health condition in ways that is not possible in other work contexts. She explained:

I'm having a really hyper vigilant day and I go to work at retail and I get aggressive customers, you have to stay there for the whole time. I can't like nip out of the room, you know? So you're under that kind of constant attack. Whereas if I'm on call [for sex work], I can just hit up my madam and be like 'look I' $m$ having a poor mental health day, I'll come into work tomorrow'. I'm real lucky with the supportive environment I have and the client base I have. (Bella)

Similarly, Jane, who worked as an independent sex worker described the flexibility of the work as having significant benefits for managing her depression. However, it also went further than this, and Jane described the sex worker community as being supportive in ways she had not found in other industries. She explained:

So, suffering from depression it's so hard to keep a job when you struggle to get out of bed in the morning, when your boss doesn't understand. And when you're your own boss and when you set your own hours it's a lot easier to just say to a client 'hey look I'm not feeling very good today can we reschedule?' And it's not the end of the world. I guess having the flexibility to fit my work in around my life has helped mentally...I know other sex workers [who] also suffer from mental illness and we can all just talk to each other...you've got this good group of people that are your friends but they're also your co-workers. You don't get that in other industries; you really don't get the support. (Jane)

Thus, the experiences of these participants clearly highlight the important role that sex work played in enabling them to have a better quality of life. For some, this meant providing a buffer from poverty and in many cases a more supportive and flexible work environment. While it is of course possible for sex workers to benefit from sex work in these ways in a range of legal contexts, the decriminalised framework provides conditions that are most conducive to these benefits being felt, through the provision of legal rights and removing the stress and fear that is inevitable under policies which seek to repress the sex industry. Amber reflected on this, explaining:

I am incredibly grateful that I'm sex working in the time of decriminalisation. It sounds very stressful to have been a sex worker before that time... If it was still criminalised I would have found it harder to be a sex worker and to have made that decision... It wouldn't change how I feel about sex work, I'd still feel like it's a perfectly fine thing to do. If it were against the law, I just know personally it would cause me a lot of stress. (Amber)

Similarly, Bella Petite described the experience of working in a decriminalised environment versus her perception of contexts in which aspects of sex work are criminalised, explaining:

...it means that I can focus on my work - I don't have to focus on how to survive dodging a crime you know?...I would have to spend my time and energy thinking of tactics to not get caught - that's really stressful. That must be a very stressful situation for people to be in because you're going to be stressed out just thinking about doing the job, thinking that you're doing to be caught. So, I don't have those concerns in a country where it's decriminalised. (Bella Petite)

Thus, decriminalisation was critical in enabling participants to work without unnecessary stress, meaning that the benefits of sex work could be more easily experienced, providing more respite from the economic pressures of society. The fact that several participants used sex work as a strategy to improve their lives in the context of low paid work, long hours and exploitative working conditions is far from surprising. Sex workers' rights activists have called attention to the impact of poverty and financial insecurity in influencing decisions to engage in sex work for decades (see for example Leigh, 1989; English Collective of Prostitutes, 2016). However, these experiences also demonstrate how the decriminalisation of sex work serves to mitigate against the harms of Neoliberal societies. Policies which criminalise aspects of sex work render sex work more difficult, thus making people's lives harder, heaping stress on top of stress. Decriminalisation, as the experiences of participants demonstrate, means that people can use sex work as a legitimate strategy to improve their quality of life without the anxiety 
and stress of having to evade authorities. However, the benefits of sex work for participants were not only financial, and also related to the freedom and opportunities that sex work afforded, which was conducive to their autonomy.

\section{Autonomy Harms: Freedom and the Power to Choose}

Autonomy harms, Pemberton argues, 'result from situations that fundamentally disrupt our attempts to achieve self-actualisation' (2015, p. 105). People can only achieve self-actualisation if they are afforded sufficient autonomy to make choices and act accordingly. When people lack control over their lives and are powerless in decision-making relating to their situations, they are harmed through this lack of autonomy (Pemberton, 2015).

Thus, in the context of sex work, it can be argued that self-actualisation is only possible when sex workers are afforded labour rights. When sex work is criminalisedwhether it be focused on sex workers, their clients or other third parties, sex workers lack control over their work environment and work conditions. Autonomy is also undermined at a fundamental level because the state has decided that people should not engage in sex work, regardless of why they may want or need to. This undermining of autonomy through oppressive laws, coupled with socio-economic conditions under capitalism described in the previous section, forces people into a very precarious position where they are harmed in multiple ways that could reasonably be avoided. Decriminalisation supports autonomy because it respects individual decision-making about working in the sex industry and affords sex workers more control over their working conditions.

The positive impact of decriminalisation on autonomy was evident in participants' experiences. Amber, for example, explained that the freedom to engage in sex work in New Zealand opened a new way of life for her that she had not previously imagined. She had made this decision after reading an interview with a brothel manager and a sex worker in a magazine. She explained:

I spent my life stressing about this idea of a job and a passion that you're tied to-this thing to make money for years and years and years, and then you only really get what you want much later in life. That just never really appealed to me. And it was in about 2008 I was reading an article about a place similar to where I'm working now... And yep from that point I was like 'right that's how I'm going to earn my living so I can lead the life that I want to lead'. (Amber)

The freedom engaging in sex work enabled was also evident in the experiences of several participants. For
Amanda, sex work had provided more freedom to spend time with her children, in addition to a broader feeling of freedom that was not possible in other forms of work. She explained:

I have much more freedom with my children and being able to send them on camps and things like that without having to stress about saving a dollar each week for five years to pay for something. I mean it's not just the money-it never has or will be, but it makes you feel more freer than when you have the weight on your shoulders because of what it affords you... it affords me the freedom to be there in the presence of the children and that's great. (Amanda)

Amy similarly explained how sex work had a transformative impact on her life due to the autonomy it afforded her:

...more money, more freedom. You can choose more time to do the stuff that you want to do. [People say] 'I have to work, I have to pay the bills-I can't spend time with my kids'. But in this industry, you can choose the time that you want to do and then you save money and you can have a lot of time with your kids. Brilliant. (Amy)

Strengthened autonomy was also evident in the sense of control that participants had in the course of their work in the decriminalised context, echoing the findings of previous research undertaken in the initial years post-decriminalisation (see for example Abel, 2014; Armstrong, 2014). While critics of decriminalisation have inferred that sex workers now have less control and choice in their work (see Armstrong, 2020 and Coughlan, 2017 for examples), participants in this project were unequivocal that the decriminalised environment afforded them more choice and control. Sophie, for example, described feeling supported by the operator of the agency she worked in, and related this to the laws in place. She explained:

...the legal system here is like, it's nice you know?

Like people at my work are so comfortable and happy

to be there and you just know that no one is worrying about dodgy stuff happening. And we all have so much trust in our employer who like absolutely won't tolerate any dodgy stuff and you do get that sense of the law being behind all of that. (Sophie)

This experience described by Sophie echoes the findings of other recent research with sex workers who work in managed environments. Abel and Ludeke (2021) found that while challenges certainly remained for brothel-based sex workers, decriminalisation has provided an environment in which there is increased scope for sex workers to experience 
working conditions that are safer and more supported than they are when aspects of sex work are criminalised.

The control afforded by the PRA was also helpful in interactions with clients. Amber explained, 'I like touting laws around sex work, like to clients if it's useful. I like having that as a tool if needed'. This was also expressed by Jordan who explained 'they know we have labour rights and we will use them against them if they don't behave themselves'. While research with clients of sex workers in New Zealand has been scant, research that has been undertaken does indicate an awareness among clients of the rights that sex workers have in the decriminalised environment (Mower, 2020). The autonomy afforded by decriminalisation was also described by Jordan as leading to more straightforward and positive interactions with clients. While she had not ever worked in a criminalised context, she felt that this would have an adverse effect on interactions with clients, explaining:

I think if it was something that was illegal the communication between sex worker and client would be very different. I've never experienced it, but I assume that type of communication would be very stilted and hard. Whereas here, you know, I build a lot of great relationships with clients and also they can approach you in a much more relaxed manner. (Jordan)

Thus, the experiences of these participants highlight how the freedom to engage in sex work without the risk of either themselves or their clients being criminalised had not only had a significant impact on their quality of life, enabling them to live their lives in ways that were not possible in other occupations, it had also strengthened their autonomy in the context of their work.

\section{Relational Harms: Recognition and Respect}

Relational harm, Pemberton notes, comes in two forms. The first are harms that stem from 'enforced exclusion from social relationships' (2015, p. 30). The second are harms that occur from misrecognition, where people's identities are misrepresented with few options to correct these misrepresentations (Pemberton, 2015). As a stigmatised population, sex workers are clearly impacted by relational harms. The stigma associated with sex work is well-documented (see for example Sallman, 2010; Bruckert, 2012; Benoit et al., 2018, 2019). While sex workers in a range of legislative environments are impacted by stigma, this is most pronounced when the sex industry is subject to criminalisation, through inferring that those involved in it are dangerous and problematic (Krüsi et al., 2014). Criminalisation creates an additional barrier to sex workers being able to talk openly about their work due to the risks of doing so, meaning that many people are forced to compartmentalise a part of their life through fear of these consequences (Armstrong \& Fraser, 2020).

While stigma was still undoubtedly an issue in the decriminalised context, several participants in this study felt that decriminalisation sent an important message about sex work that had positive implications for how sex workers are viewed. For example, Lucy explained:

I think the law [the PRA] definitely helps to legitimise it and reduce a lot of the stigma. I mean not all but I think it definitely helps because you're not like 'a criminal' which, you know, is nice. (Lucy)

Jane felt similarly to Lucy and explained why she felt the decriminalisation was so important as a starting point to shift perceptions relating to sex work:

If the government is saying to its people that sex work is illegal, then the people are going to think it's wrong. If the government is saying 'sex work is fine'...then why would society see anything wrong with it, if the government's saying 'yep do your thing?' So yes I think it [decriminalisation] makes a massive difference. (Jane)

Bella Petite felt that the recognition that decriminalisation afforded sex workers, which defines them as workers, signalled a degree of acceptance, which was reassuring to her, explaining:

...it's an unspoken gesture, if you like, where it's accepting. I mean it's giving like an acceptance of what I'm doing for starters because it's decriminalised 'okay yeah my country accepts this, my government accepts this. That's a good start'. (Bella Petite)

Echoing the findings of previous research that has found that relationships between police and sex workers have improved significantly since decriminalisation (see for example Abel et al., 2007; Armstrong, 2016), several participants expressed confidence in the police that they did not feel would be possible if sex work were not decriminalised. Bella for example explained, 'I have an expectation that the police will listen... it is their job to care now about my safety'. She felt that if the sex industry was subject to criminalisation, this would not be as likely, stating 'it's hard for them to care about our safety if they automatically see us as criminals-like if they see our work as illegal and a crime'. Amy, an Asian sex worker, described an adverse experience she had with a client who would not respect her boundaries and felt entitled to treat her that way, and how the police had responded when they arrived. She recalled 'the policeman just said [to him] "You shut up! The sex worker, they are just a doing job-they're normal. You shouldn't like treat women, treat her, like that". So, I think it's the law that help the society or the police to protect us'. 
The significance of sex work not being defined as crime was emphasised by several participants specifically in terms of how they felt it impacted their treatment, not only by police, but also in other day to day interactions. Jordan for example explained how telling an accountant about what she did was not an issue because 'he was of the mindset "well it's decriminalised-you're not doing anything wrong"".

Thus, while stigma is still omnipresent, the experiences and perceptions of participants indicate positive shifts. As I have argued previously, while there is no law change that can eradicate stigma, decriminalisation does to some extent reduce its power as an exclusionary force (see Armstrong, forthcoming 2021). Luke explained what he imagined it would be like to work in a context in which either sex workers or their clients were criminalised, and the impact he felt decriminalisation had, noting:

I don't think my perspective on the nature of the work I'm doing would change [if sex work was not decriminalised], but the way that I go about it would have to change. I would also be significantly less willing to tell people what I do, particularly coming back to like telling my family or my loved ones...People will always have issues with this because of narratives we've received around sex, bodies, and labour, and conflating those things. I don't think that changing the law will change people's views-it just doesn't give them a legal platform to do shitty things because of those views. (Luke)

Thus, while sex workers in all legislative contexts are subject to relational harms in the form of stigma and exclusion, the decriminalisation of sex work works against these harms to some extent by reducing opportunities to weaponise stigma against sex workers. It provides a context in which such harms can be more readily challenged, where they are less likely to occur in the first place, in which sex workers are more likely to feel recognised and respected.

\section{Conclusion}

In this paper, I sought to examine the utility of social harm as a framework for understanding the implications of sex work policies, using the decriminalisation of sex work in New Zealand as a case study. The decriminalisation of sex work remains extremely rare in the global context, despite the steadfast advocacy of sex workers. Instead, most countries continue to adopt and extend variants of criminalisation, with the criminalisation of clients and other third parties becoming more prevalent. Such policies are based on an ideological belief that sex work is inherently harmful. These criminalising policies are intended to address this presumed harmfulness by repressing the sex industry, with the goal of eradicating it. This approach overlooks the reality that sex work helps to sustain people economically in ways that are not possible in other forms of work in capitalist societies. It enables people who are chronically ill to work more flexibly, affords committed students the ability to work fewer hours, allows parents more time to spend caring for their children and supports the survival of people struggling with addiction and poverty. As the experiences of sex workers documented in this paper demonstrate, sex work helps people to meet their fundamental human needs, which are often compromised by disempowering socio-economic conditions.

As highlighted throughout the paper, social harm-and specifically Pemberton's (2015) human needs focused approach-is a particularly useful framework for understanding sex work policies and their various implications. It serves to illuminate the harms of societies structured by Neoliberal economic policies, which influences decisions to do sex work among many people. It further highlights the harms of policies seeking to repress the sex industry via criminalisation, which aspire to remove sex work as an option for people. Such policies compound societal conditions that are already harmful, creating additional harms relating to physical and mental wellbeing, autonomy, recognition and social inclusion. The social harm approach subsequently enables governments pursuing repressive sex work policies to be more clearly identified as primary perpetrators of harm towards sex workers.

The experiences of sex workers interviewed for this research highlight how decriminalising sex work works to reduce harms in a myriad of ways. While decriminalisation alone is not enough to change attitudes, defining sex work as work and providing rights inferred to participants that the state cared about their safety. Participants spoke of the decriminalised context as providing reassurance and surmised that the criminalisation of either themselves, their clients or managers would create a context of considerable stress and anxiety.

These findings are not surprising. Sex worker-led organisations have long called attention to the role of poverty and inequality in influencing involvement in sex work and the need for decriminalisation to improve the lives of sex workers trying to navigate oppressive neoliberal societies (English Collective of Prostitutes, 2016; Mac \& Smith, 2018). Within sex work policy debates, governments frequently fixate on harms that can occur within sex work and ponder whether sex work itself is harmful. However, experiences of participants who took part in this research clearly illustrate how engaging in sex work made their lives better. Thus, when considering the issue of harm, governments would be better placed to look inwards towards the harm that they perpetrate themselves through socio-economic policies that create inequality and precarity, and repressive sex work policies which compound these harms. While decriminalisation 
is not a panacea for social justice in that it cannot undo the harms of poverty, inequality and exploitation caused by the state, it can help to mitigate against these harms by making sex work a safer and more accessible option for those who choose to engage in it.

Acknowledgements The author wishes to sincerely thank all the participants who shared their knowledge and experiences in interviews, and Cherida Fraser who assisted with interviewing for both projects.

Funding The research was funded by a Marsden Fast Start grant and a Victoria University of Wellington Research Development Grant.

Availability of Data and Material The data are not publicly available due to its sensitive nature and the risk to the privacy of research participants.

\section{Declarations}

Competing Interests The author declares no competing interests.

\section{References}

Abel, G. (2014). A decade of decriminalization: Sex work 'down under' but not underground. Criminology \& Criminal Justice, 14(5), 580-592. https://doi.org/10.1177/1748895814523024

Abel, G. (2018). Decriminalisation and social justice: A public health perspective on sex work In S. a. M. Fitzgerald, K. (Ed.), Realising Justice for Sex Workers: An Agenda for Change Rowman and Littlefield.

Abel, G., Fitzgerald, L., \& Brunton, C. (2007). The Impact of the Prostitution Reform Act on the Health and Safety Practices of Sex Workers. Retrieved from Christchurch.

Abel, G., \& Ludeke, M. (2021). Brothels as sites of third-party exploitation? Decriminalisation and sex workers' employment rights. Social Sciences, 10(1), 3. Retrieved from https://www.mdpi.com/ 2076-0760/10/1/3

Armstrong, L. (2014). Screening clients in a decriminalised streetbased sex industry: Insights into the experiences of New Zealand sex workers. Australian \& New Zealand Journal of Criminology, 47(2), 207-222. https://doi.org/10.1177/0004865813510921

Armstrong, L. (2016). From law enforcement to protection? Interactions between sex workers and police in a decriminalized streetbased sex industry. The British Journal of Criminology, 57(3), 570-588. https://doi.org/10.1093/bjc/azw019

Armstrong, L. (2020). Decriminalisation of sex work in the post-truth era? Strategic storytelling in neo-abolitionist accounts of the New Zealand model. Criminology \& Criminal Justice. https://doi.org/ $10.1177 / 1748895820918898$

Armstrong, L. (2021). From Social Deviant to Equal Citizen? Stigma and the Decriminalisation of Sex Work in New Zealand. In J. Bjønness, L. Nencel, \& M. Skilbrei (Eds.), Reconfiguring Stigma in Studies of Sex for Sale. Routledge

Armstrong, L., Abel, G., \& Roguski, M. (2020). Fear of trafficking or implicit prejudice? Migrant sex workers and the impacts of Section 19. In L. Armstrong \& G. Abel (Eds.), Sex Work and the New Zealand Model (1 ed., pp. 113-134): Bristol University Press.

Armstrong, L., \& Fraser, C. (2020). The disclosure dilemma: Stigma and talking about sex work in the decriminalised context. In L. a. A. Armstrong, G. (Ed.), Sex Work and the New Zealand Model:
Decriminalisation and Social Change. Bristol: University of Bristol Press.

Ashford, C., Morris, M., \& Powell, A. (2020). Bareback sex in the age of preventative medication: Rethinking the 'harms' of HIV transmission. The Journal of Criminal Law, 84(6), 596-614. https:// doi.org/10.1177/0022018320974904

Bennachie, C., Pickering, A., Lee, J., Macioti, P. G., Mai, N., Fehrenbacher, A. E., Giametta, C., et al. (2021). Unfinished Decriminalization: The Impact of Section 19 of the Prostitution Reform Act 2003 on Migrant Sex Workers' Rights and Lives in Aotearoa New Zealand. Social Sciences, 10(5), 179. https://doi.org/10.3390/socsci10050179

Benoit, C., Jansson, S. M., Smith, M., \& Flagg, J. (2018). Prostitution stigma and its effect on the working conditions, personal lives, and health of sex workers. The Journal of Sex Research, 55(4-5), 457-471. https://doi.org/10.1080/00224499.2017.1393652

Benoit, C., Maurice, R., Abel, G., Smith, M., Jansson, M., Healey, P., Magnuson, D. (2019). 'I dodged the stigma bullet': Canadian sex workers' situated responses to occupational stigma. Culture, Health \& Sexuality. 1-15. https://doi.org/10.1080/13691058.2019.1576226

Bruckert, C. (2012). The mark of disreputable labour: Sex workers negotiate stigma. In S. Hannem \& C. Bruckert (Eds.), Stigma Revisited: Implications of the Mark. Ottawa: University of Ottawa Press.

Canning, V. (2019). Abject asylum: Degradation and the deliberate infliction of harm against refugees in Britain. Justice, Power and Resistance, 2(2), 37-60.

Coughlan, T. (2017). NZ's approach to sex work under fire. Newsroom.

Duff, M. (2014). Sex worker gets $\$ 25,000$ over harassment. The Dominion Post.

Ellison, G., Ní Dhónaill, C., \& Early, E. (2019). A review of the criminalisation of paying for sexual services in Northern Ireland Retrieved from Belfast.

English Collective of Prostitutes. (2016). Decriminalisation of prostitution: The evidence Retrieved from https://prostitutescollective.net/ wp-content/uploads/2016/11/Online-Report.pdf

Farley, M. (2004). 'Bad for the body, bad for the heart': Prostitution harms women even if legalised or decriminalised. Violence Against Women, 10.

Fraser, N. (2003). Social justice in the age of identity politics: Redistribution, recognition, and participation. In N. a. H. Fraser, A (Ed.), Redistribution or Recognition? A Political-Philosophical Exchange. London and New York: Verso.

Hillyard, P., Pantazis, C., Tombs, S., \& Gordon, D. (2004). Introduction. In P. Hillyard, C. Pantazis, S. Tombs, \& D. Gordon (Eds.), Beyond Criminology (pp. 1-9): Pluto Press.

Hillyard, P., \& Tombs, S. (2007). From 'crime' to social harm? Crime, Law and Social Change, 48(1), 9-25. https://doi.org/10.1007/ s10611-007-9079-z

Hillyard, P., \& Tombs, S. (2004). Beyond criminology? In D. Dorling, D. Gordon, P. Hillyard, C. Pantazis, S. Pemberton, \& S. Tombs (Eds.), Criminal obsessions: Why harm matters more than crime. Centre for Crime and Justice Studies.

Honneth, A. (1995). Struggle for recognition - The moral grammar of social conflicts. Polity Press.

Jeffreys, S. (1997). The idea of prostitution North Melbourne: Spinifex, .

Kingston, S., \& Thomas, T. (2019). No model in practice: A 'Nordic model' to respond to prostitution? Crime, Law and Social Change, 71(4), 423-439. https://doi.org/10.1007/s10611-018-9795-6

Knifton, L., \& Inglis, G. (2020). Poverty and mental health: Policy, practice and research implications. Bjpsych Bulletin, 44(5), 193196. https://doi.org/10.1192/bjb.2020.78

Krüsi, A., Pacey, K., Bird, L., Taylor, C., Chettiar, J., Allan, S., \& Shannon, K. (2014). Criminalisation of clients: Reproducing vulnerabilities for violence and poor health among street-based sex workers in Canada - a qualitative study. British Medical Journal Open, 4(6), e005191. https://doi.org/10.1136/bmjopen-2014-005191 
Lasslett, K. (2010). Crime or social harm? A dialectical perspective. Crime, Law and Social Change, 54(1), 1-19. https://doi.org/10. 1007/s10611-010-9241-x

Leigh, C. (Writer). (1989). Outlaw poverty, not prostitutes. In C. Leigh (Producer). San Francisco.

Levy, J. (2014). Criminalising the purchase of sex: Lessons from Sweden London Routledge.

Livingstone, H. (2020). New Zealand sex worker wins six-figure sexual harassment payout. The Guardian.

Lloyd, A. (2018). The harms of work: An ultra-realist account of the service economy (1 ed.). Bristol Bristol University Press.

Mac, J., \& Smith, M. (2018). Revolting Prostitutes: The Fight for Sex Workers' Rights. Verso Books.

Marsh, S. (2019). Decriminalise sex work to protect us from crime, prostitutes say. The Guardian.

Mason, B. (2018). Dame Catherine Healy 'brought in from the cold' after career advocating for sex workers. Stuff.

Mason, W. (2019). 'No one learned': Interpreting a drugs crackdown operation and its consequences through the 'lens' of social harm. The British Journal of Criminology, 60(2), 382-402. https://doi. org/10.1093/bjc/azz047

Mower, S. (2020). "My dollar doesn't mean i've go any power or control over them": Clients speak about purchasing sex. In L. a. A. Armstrong, G. (Ed.), Sex Work and the New Zealand Model: Decriminalisation and Social Change. Bristol: Bristol University Press.

O’Neill, M., \& Laing, M. (2018). Sex worker rights, recognition and resistance In S. Fitzgerald \& K. McGarry (Eds.), Realising Justice for Sex Workers: An Agenda for Change (pp. 161-183). London Rowman \& Littlefield.

Östergren, P. (2017). From zero tolerance to full integration. Rethinking prostitution policies. Retrieved from https://www.demandat. eu/publications/zero-tolerance-full-integration-rethinkingprostitution-policies: https://www.demandat.eu/publications/ zero-tolerance-full-integration-rethinking-prostitution-policies

Pemberton, S. (2007). Social harm future(s): Exploring the potential of the social harm approach. Crime, Law and Social Change, 48(1-2), 27-41. https://doi.org/10.1007/s10611-007-9078-0

Pemberton, S. (2015). Harmful societies: Understanding social harm. Bristol Policy Press.

Prostitution Reform Act. (2003). https://www.legislation.govt.nz/act/ public/2003/0028/latest/DLM197815.html
Sallmann, J. (2010). Living with stigmA: Women's experiences of prostitution and substance use. Affilia, 25(2), 146-159. https:// doi.org/10.1177/0886109910364362

Sanders, T. (2016). Inevitably violent? Dynamics of space, governance, and stigma in understanding violence against sex workers. In Special Issue: Problematizing Prostitution: Critical Research and Scholarship (pp. 93-114).

Sanders, T., \& Campbell, R. (2014). Criminalization, protection and rights: Global tensions in the governance of commercial sex. Criminology \& Criminal Justice, 14(5):535-548.https://doi.org/ $10.1177 / 1748895814543536$

Scoular, J., \& Carline, A. (2014). A critical account of a 'creeping neo-abolitionism': Regulating prostitution in England and Wales. Criminology and Criminal Justice, 14(5), 608-626. https://doi. org/10.1177/1748895814543534

Scoular, J., \& O’Neill, M. (2007). Regulating prostitution: Social inclusion, responsibilization and the politics of prostitution reform. The British Journal of Criminology, 47(5), 764-778. https://doi.org/ 10.1093/bjc/azm014

Soliman, F. (2019). States of exception, human rights, and social harm: Towards a border zemiology. Theoretical CRiminology. https:// doi.org/10.1177/1362480619890069

Sutherland, E. (1945). Is "white collar crime" crime? American Sociological Review 10(2), 132-139. (2003).

Tyler, I. (2020). Stigma: The machinary of inequality London Zed Books.

Vanwesenbeeck, I. (2017). Sex work criminalization is barking up the wrong tree. Archives of Sexual Behavior, 46(6), 1631-1640. https://doi.org/10.1007/s10508-017-1008-3

Vuolajärvi, N. (2019). Governing in the name of caring - the Nordic model of prostitution and its punitive consequences for migrants who sell sex. Sexuality Research and Social Policy, 16(2), 151165. https://doi.org/10.1007/s13178-018-0338-9

Wellington District Courts Reporter. (2021). Rape by removing a condom earns three-year, nine-month prison term. Stuff.

Yar, M. (2012). Critical criminology, critical theory and social harm. In Hall \& S. Winlow (Eds.), New Directions in Criminological Theory. Routledge

Publisher's Note Springer Nature remains neutral with regard to jurisdictional claims in published maps and institutional affiliations. 